\title{
Pretreatment enhanced the physical and antioxidant stability of dried Cordyceps militaris by different drying conditions
}

\author{
Dechapon Chaiya ${ }^{l}$, Chanthima Phungamngoen ${ }^{1 *}$, Sunee Eadmusik ${ }^{1}$, Wichien Sriwichai $^{2}$ and Ekkasit Subcharoen $^{3}$ \\ ${ }^{1}$ Department of Agro-industry and Management, Faculty of Agro-industry, King Mongkut's University of Technology North Bangkok, \\ Prachinburi 25230, Thailand \\ ${ }^{2}$ Department of Innovation and Product Development Technology, Faculty of Agro-industry, King Mongkut's University of Technology \\ North Bangkok, Prachinburi 25230, Thailand \\ ${ }^{3}$ ACX Herb Co., Ltd., Prachinburi 25230, Thailand
}

\begin{abstract}
Cordyceps militaris has been treated as a functional food and supplementary food for several years. In recent studies, active components in Cordyceps militaris have received great attention and promoted health. Drying technology is a common method and it was applied to Cordyceps spp. many times for extending their shelf life and preserving their nutrients. A combination of pretreatment with drying technology could promote processing efficiency. The aim of this study is to study the effect of pretreatments (Soaking in $0.5 \%$ citric acid, boiling, steaming and desiccating) combined with drying method by vacuum dryer (VD) at 50, 60 and $70{ }^{\circ} \mathrm{C}$ on physical quality and antioxidant capacity in dried Cordyceps militaris. The result showed pretreatment by soaking in acid $0.5 \%$ citric acid, boiling and steaming took drying time more than those desiccating and untreated dried sample to desire the final moisture content (approximately $8 \% \mathrm{db}$.). Increasing of drying temperature in VD could reduce drying time. Desiccating prior to drying samples exhibited the highest $L^{*}$ value and the lowest of $a^{*}$ and $b^{*}$ values when compared with other pretreatments. High drying temperature tend to decrease $L^{*}$ value while $a^{*}$ and $b^{*}$ values are increasing. It was due to the occurring of browning reaction during drying process. Desiccating samples showed color value closest to fresh samples. These results were consistent with all photographs from digital camera. The glass transition temperature of all samples was about $39.43-45.82{ }^{\circ} \mathrm{C}$ and the highest value was found in the case of desiccating sample. Antioxidant properties, pretreatment by soaking in acid combined with drying at $70{ }^{\circ} \mathrm{C}$ by VD showed the highest content of phenolic compound, DPPH and superoxide radical scavenging activity. It was concluded that pretreatment could preserve important substances, for example, cordycepin and adenosine contents of Cordyceps militaris during drying.
\end{abstract}

Keyword. Antioxidant, Cordyceps, Drying, Pretreatment

\section{Introduction}

Cordyceps militaris is a member of the fungus. It has been being interested by many countries in Asia and used to be functional food and supplementary foods for several years [1]. Pharmacological properties in C. militaris have showed antioxidant, anti-inflammatory and antidiabetic activities. C. militaris consists of nucleosides and active compounds such as adenine, cordycepin, polysaccharide and phenolic compound which could be promoted antioxidant capacity [2]. C. militaris has a short shelf life and deteriorate immediately in post-harvest [3]. Drying is common method use for extend shelf life of Cordyceps spp.

Normally, dried Cordyceps spp. was applied by hot air dryer at $50{ }^{\circ} \mathrm{C}$ [4]. Hot air drying has been showed low energy consumption and low cost. The increasing of drying temperature resulted in increase of drying rate and drying time decrease. The shorter of drying time led to lower energy consumption [5]. However, hot air drying showed long drying time leading to quality degradation [6]. Vacuum drying is operating under oxygen-free condition and low temperature. It has been showed shorter drying time and improve the quality of dried product compared with traditional drying process [7]. Applied low temperature under low pressure of vacuum drying exhibited the high levels of total phenolic compound and antioxidant capacity in Robusta wet coffee pulp [8]. ABTS radical scavenging activity also showed higher level of vacuum dried Paramignya trimera root than those form hot air drying [9]. For the novel drying technologies were used in $C$. militaris for preserving the degradation of bioactive compounds. For example, Wu et al. [10] studied effect of infrared drying on quality of $C$. militaris reported that infrared drying temperature at $60{ }^{\circ} \mathrm{C}$ was the optimal condition to

* Corresponding author: chanthima.p@agro.kmutnb.ac.th 
maintain the adenosine, cordycepin and total phenolics. $\mathrm{Wu}$ et al. [11] studied the combination of drying technologies by microwave assisted pulse fluidized bed freeze-drying (MPFFD) on C. militaris. It was found that MPFFD could preserve bioactive compounds of product. However, industries usually use a common drying methods; hot air drying and vacuum drying for producing dried products. Pretreatment was used prior to drying. It showed many advantages such as reducing the initial load of microorganism and inactivate enzymatic activity in vegetables [12]. Pretreatment by blanching is usually combine with drying process for inhibit enzymatic browning reaction. It could promote color retention of product [13] and reduce the pathogens on product surface $[14,15]$. The $\beta$-carotene retentions of acid pretreated carrot exhibited unchanged during drying while untreated showed continuously decreased [16].

As mentioned above, there are many researches study on the effect of drying methods on quality of C. militaris. However, the combinations effect of pretreatment and drying is still lacking. The aim of this work is to study the physical quality and antioxidant stability of dried $C$. militaris by the combine effect of pretreatments and vacuum drying at different drying temperature. The application of this study could be use to guideline for the consumer to produce dried $C$. militaris.

\section{Materials and methods}

\subsection{Raw material}

Fresh C. militaris (cultivated indoor) size is $7-10 \mathrm{~cm}$. length and $3 \mathrm{~mm}$. diameter. Samples were obtained from ACX herb Co., Ltd. (Prachinburi province, Thailand). They were cultured in rice. Samples were washed, drained and stored at $4{ }^{\circ} \mathrm{C}$ before conducted the experiments.

\subsection{Pretreatments}

Samples were pretreated with different methods prior to drying. (1) Soaking in $0.5 \%(\mathrm{v} / \mathrm{v})$ of citric acid at the sample to acid solution ratio of 1: 10 for $3 \mathrm{~min}$. (2) Boiling sample in hot water at temperature of $\sim 97{ }^{\circ} \mathrm{C}$. The ratio between the sample and boiled water was 1: 5 for 3 min. (3) Steam blanching in water bath (WNE 29, Memmert, Germany) at $95{ }^{\circ} \mathrm{C}$ for $3 \mathrm{~min}$. (4) Desiccating in the room $\left(25^{\circ} \mathrm{C}\right)$ for $12 \mathrm{~h}$.

\subsection{Drying conditions}

Pretreated samples were then dried by vacuum dryer (VO500, Memmert, Germany). The drying temperatures were 50,60 and $70{ }^{\circ} \mathrm{C}$ under pressure of 60 mbar. $100 \mathrm{~g}$ of C. militaris was placed in a single layer on the tray. The final moisture content was below $8 \%(\mathrm{db})$. Drying time was obtained from the drying curves.

\subsection{Moisture content and water activity analysis}

The moisture content was evaluated follow AOAC [17]. Sample was dried at $105{ }^{\circ} \mathrm{C}$ in an oven until constant weight and then calculated moisture content of product using a standard gravimetric method. A water activity $\left(a_{\mathrm{w}}\right)$ of $C$. militaris was analyzed by a water activity meter (Series 3TE, AquaLab, Washington).

\subsection{Color measurement}

Color of C. militaris was determined using a colorimeter (ColorFlex, HunterLab, Virginia). Ground sample was put in a cuvette. After the calibration a sample was placed inside the chamber and then analyzed the color. The lightness $\left(L^{*}\right)$, redness or greenness $\left(a^{*}\right)$, yellowness or blueness $\left(b^{*}\right)$ and $\Delta E$ were used to describe the total color difference between fresh and dried samples.

\subsection{Micrograph of dried C. militaris by Field Emission Scanning Electron Microscope (FE- SEM)}

The appearance of different dried C. militaris was evaluated follow methods of Voda et al. [18] with some modifications. Dried C. militaris was broke into two parts for observing a cross-section. The surface of sample was coated with platinum before measuring. The sample was put on to a chamber of field emission scanning electron microscope (Auriga, Zeiss, Germany) at $30 \times$ magnification to study the characteristics of dried C. militaris.

\subsection{Glass transition temperature measurement}

$\left(T_{g}\right)$

The transition temperature $\left(\mathrm{T}_{\mathrm{g}}\right)$ of different dried $C$. militaris was evaluated follow methods of Cao et al. [19] with some modifications. A differential scanning calorimeter (DSC3+, Mettler-Toledo, Switzerland) was applied to analysis. About $4 \mathrm{mg}$ of dried samples were filled and encapsulated into a DSC aluminum pan (40 $\mu \mathrm{L})$. An empty aluminum pan was used as a reference. Samples were cooled from room temperature to $-20^{\circ} \mathrm{C}$, held for 2 min and heated from -20 to $180{ }^{\circ} \mathrm{C}$ at 10 ${ }^{\circ} \mathrm{C} / \mathrm{min}$. Then they were cooled from 180 to $-20^{\circ} \mathrm{C}$ at 50 ${ }^{\circ} \mathrm{C} / \mathrm{min}$ and reheated again to $180^{\circ} \mathrm{C}$ at $10{ }^{\circ} \mathrm{C} / \mathrm{min}$.

\subsection{Total phenolic compound analysis}

Total polyphenol content (TPC) of different dried $C$. militaris was measured by the colorimetric FolinCiocalteu method according to Chen et al. [20] with minor modifications. Firstly, $1 \mathrm{~mL}$ of $C$. militaris extracts was mixed with $5 \mathrm{~mL}$ of Folin-Ciocalteu's reagent $(1: 10, \mathrm{v} / \mathrm{v})$. Then the solution was blend with 4 $\mathrm{mL}$ of sodium carbonate solution $(7.5 \%)$. The mixture was heated at $45^{\circ} \mathrm{C}$ for $15 \mathrm{~min}$ and the absorbance was determined at $765 \mathrm{~nm}$. 


\subsection{Antioxidant activity}

Dried sample $(1 \mathrm{~g})$ was extracted with $100 \mathrm{~mL}$ of boiling water for $3 \mathrm{~min}$. The solution was filtrated by No.1 filter paper for determine the antioxidant activity.

DPPH radical scavenging activity was evaluated following Mao et al. [21] with a minor modification. The extraction $(200 \mu \mathrm{L})$ was mixed with $600 \mu \mathrm{L}$ of $0.2 \mathrm{mM}$ 2,2-diphenyl-1-picrylhydrazyl (DPPH) and $5200 \mu \mathrm{L}$ of $85 \%$ ethanol. Then the mixture was hold in the dark room for $30 \mathrm{~min}$. The absorbance was measure at 515 $\mathrm{nm}$. The calculation of percentage DPPH scavenging effect was calculated as follow:

$$
\text { Scavenging activity }(\%)=\left[1-\left(\frac{A_{S}-A_{S 0}}{A_{0}}\right)\right] \times 100
$$

Where $\mathrm{A}_{0}$ was the absorbance of DPPH, $\mathrm{A}_{\mathrm{s}}$ was the absorbance of sample and $A_{\mathrm{s} 0}$ was the absorbance of sample without DPPH.

Superoxide anion radical scavenging activity follow the 1,2,3-trihydroxybenzene method [22] with minor modifications. The extraction and $0.4 \mathrm{~mL}$ of $1,2,3-$ trihydroxybenzene were added to the Tris- $\mathrm{HCl}$ buffer (4.5 mL, $0.05 \mathrm{M}, \mathrm{pH} 8.2$ ). After incubating at $25^{\circ} \mathrm{C}$ for 5 $\mathrm{min}$, the reaction was terminated by the addition of 0.1 $\mathrm{mL}$ of $\mathrm{HCl}(8 \mathrm{M})$. The mixture $(1 \mathrm{~mL})$ diluted with $2 \mathrm{~mL}$ of distilled water. Absorbance of the mixture was measured using a UV-Vis Spectrophotometer (Libra S22 Biochrom, United Kingdom) at $299 \mathrm{~nm}$. The superoxide anion radical scavenging activity was expressed as:

Scavenging activity $(\%)=\left(1-\frac{A_{2}-A_{1}}{A_{3}}\right) \times 100 \%$

Where $A_{2}$ is the absorbance of the sample, $A_{1}$ is the absorbance of the control and $\mathrm{A}_{3}$ is the absorbance of the blank sample.

\subsection{Statistical analysis}

Analysis of variance (ANOVA) was used to obtain the mean value of the results and the standard deviation using the IBM Statistical Package for the Social Sciences (SPSS, IBM Inc., Chicago, Illinois) software, version 21.0. The significant difference between two mean values was calculated using Duncan's multiple range tests at the 5\% significance level. Three replicates were used for each treatment.

\section{Results and discussion}

\subsection{Moisture content}

The initial moisture content in fresh C. militaris was about $532.59 \pm 6.14 \% \mathrm{db}$. Evolution of moisture content during drying are showed in Fig. 1. Moisture content in the cases of desiccating pretreatment and high drying temperature decreased at much higher rates than others; this observation agrees well with the previously reported results of Thirugnanasambandham and Sivakumar [7]. The final moisture content in dried samples was controlled below $8 \% \mathrm{db}$., the drying times are shown in Table 1. Drying time decreased as the drying temperature increased. This is because higher drying temperature could evaporate the moisture from food matrix easily [8]. A desiccating sample resulted lowest of drying time compared with other pretreatments. The shortest drying time could explain the lowest energy consumption [5]. In the case of steam blanching showed the highest drying time. This might be due to during the desiccating pretreatment moisture removal from plant cell while soaking in acid, boiled water blanching and steam blanching leading to high initial moisture content before drying. Nonthermal pretreatment (soakind in acid and desiccating pretreatment) exhibited lower of energy consumption than thermal pretreatment (boiling and steaming pretreatment) in the combination between pretreatments and drying process of fruits and vegetables [23].

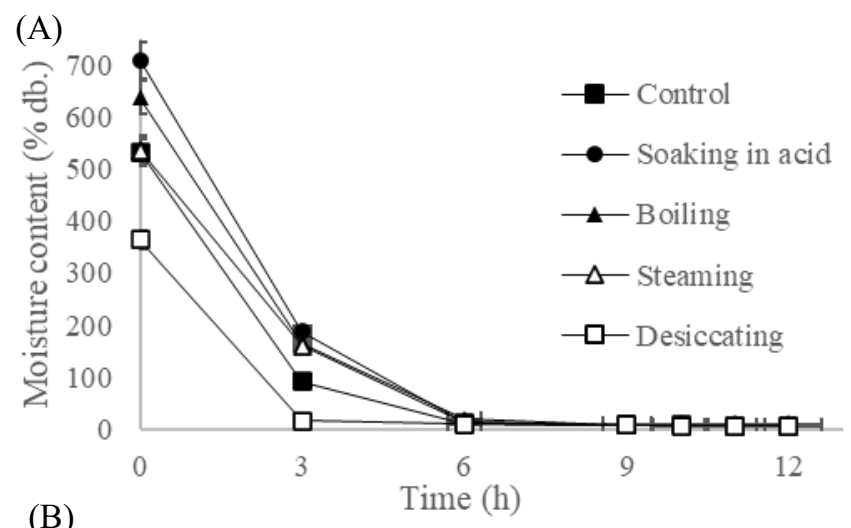

(B)
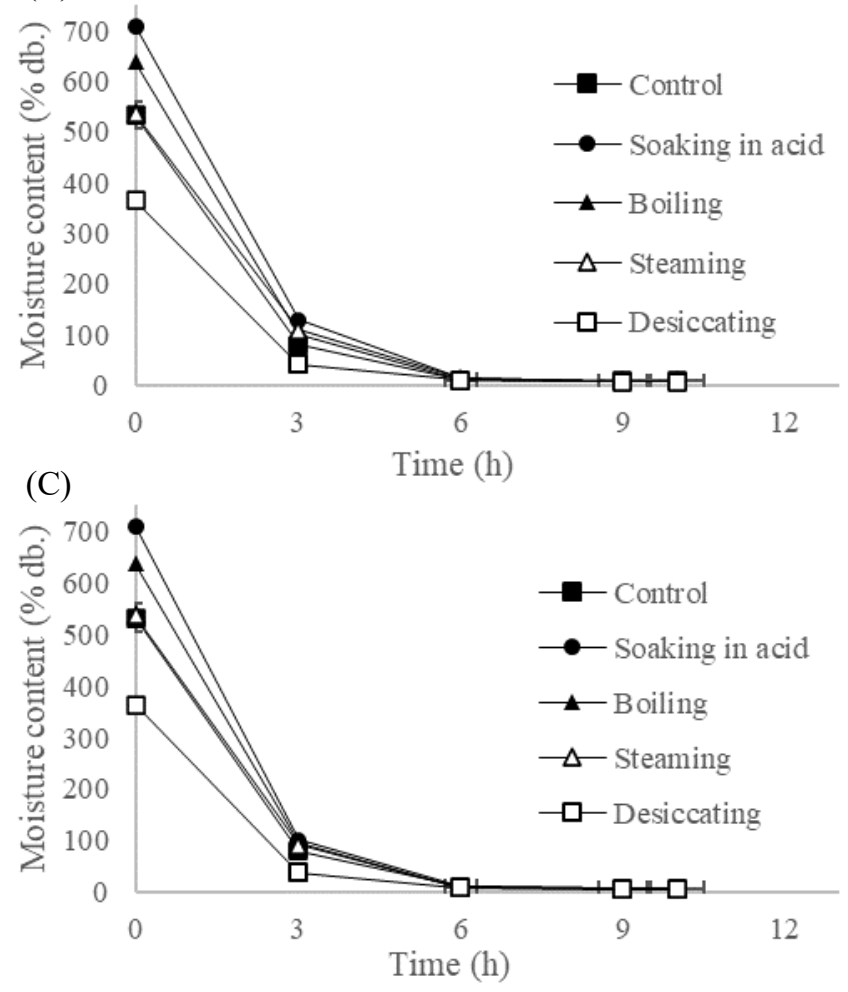

Fig. 1. The drying curves of pretreated $C$. militaris at different drying temperature : (A) $50{ }^{\circ} \mathrm{C}$, (B) $60{ }^{\circ} \mathrm{C}$ and (C) $70^{\circ} \mathrm{C}$. 
Table 1. The drying time, final moisture content, water activity and glass transition temperature of dried C. militaris.

\begin{tabular}{|c|c|c|c|c|c|}
\hline Temperature $\left({ }^{\circ} \mathrm{C}\right)$ & Pretreatment & Drying time (hr) & Final moisture content $(\%)$ & $\begin{array}{c}\text { Water activity } \\
\left(a_{w}\right)\end{array}$ & Glass transition temperature $\left({ }^{\circ} \mathrm{C}\right)$ \\
\hline \multirow{5}{*}{50} & Untreated & 10 & $7.20 \pm 0.47^{\mathrm{d}}$ & $0.323 \pm 0.005^{\mathrm{e}}$ & $40.54 \pm 0.02^{\mathrm{h}}$ \\
& Soaking in acid & 10 & $7.15 \pm 0.24^{\mathrm{de}}$ & $0.309 \pm 0.002^{\mathrm{f}}$ & $41.34 \pm 0.03^{\mathrm{g}}$ \\
& Boiling & 10 & $7.10 \pm 0.06^{\mathrm{e}}$ & $0.314 \pm 0.004^{\mathrm{f}}$ & $39.43 \pm 0.07^{\mathrm{k}}$ \\
& Steaming & 10 & $7.21 \pm 0.81^{\mathrm{d}}$ & $0.344 \pm 0.003^{\mathrm{d}}$ & $40.21 \pm 0.23^{\mathrm{ij}}$ \\
& Desiccating & 10 & $7.45 \pm 0.26^{\mathrm{c}}$ & $0.373 \pm 0.003^{\mathrm{a}}$ & $42.96 \pm 0.07^{\mathrm{c}}$ \\
\hline \multirow{5}{*}{60} & Untreated & 8 & $7.78 \pm 0.40^{\mathrm{a}}$ & $0.314 \pm 0.002^{\mathrm{f}}$ & $42.08 \pm 0.02^{\mathrm{e}}$ \\
& Soaking in acid & 8 & $7.39 \pm 0.37^{\mathrm{c}}$ & $0.308 \pm 0.001^{\mathrm{f}}$ & $42.16 \pm 0.01^{\mathrm{e}}$ \\
& Boiling & 8 & $7.37 \pm 0.43^{\mathrm{c}}$ & $0.371 \pm 0.002^{\mathrm{a}}$ & $39.98 \pm 0.08^{\mathrm{j}}$ \\
& Steaming & 8 & $7.19 \pm 0.65^{\mathrm{d}}$ & $0.322 \pm 0.002^{\mathrm{e}}$ & $41.39 \pm 0.12^{\mathrm{g}}$ \\
& Desiccating & 8 & $7.08 \pm 0.44^{\mathrm{a}}$ & $0.359 \pm 0.001^{\mathrm{b}}$ & $44.74 \pm 0.08^{\mathrm{b}}$ \\
\hline \multirow{5}{*}{70} & Untreated & 7 & $7.17 \pm 0.87^{\mathrm{d}}$ & $0.285 \pm 0.002^{\mathrm{h}}$ & $42.54 \pm 0.02^{\mathrm{d}}$ \\
& Soaking in acid & 7 & $7.14 \pm 0.10^{\mathrm{de}}$ & $0.343 \pm 0.003^{\mathrm{d}}$ & $43.07 \pm 0.04^{\mathrm{c}}$ \\
& Boiling & 7 & $7.58 \pm 0.04^{\mathrm{b}}$ & $0.353 \pm 0.002^{\mathrm{c}}$ & $40.43 \pm 0.31^{\mathrm{hi}}$ \\
& Steaming & 7 & $7.61 \pm 0.34^{\mathrm{b}}$ & $0.290 \pm 0.003^{\mathrm{g}}$ & $41.75 \pm 0.06^{\mathrm{f}}$ \\
& Desiccating & 7 & $7.42 \pm 0.65^{\mathrm{c}}$ & $0.362 \pm 0.002^{\mathrm{b}}$ & $45.82 \pm 0.14^{\mathrm{a}}$ \\
\hline
\end{tabular}

Different letters $(a-k)$ within the same column indicate a significant different $(P<0.05)$.

\subsection{The water activity and glass transition temperature}

The water activity $\left(a_{\mathrm{w}}\right)$ and glass transition temperature $\left(\mathrm{T}_{\mathrm{g}}\right)$ of dried $C$. militaris are shown (Table 1). The initial water activity of $C$. militaris was approximately $0.835 \pm 0.030$ while the dried samples is shown in a narrow range of $0.284-0.376$ due to the final moisture content was controlled. It was observed that glass transition temperature was in range of 39.41 $45.63{ }^{\circ} \mathrm{C}$. Increasing drying temperature resulted in $\mathrm{T}_{\mathrm{g}}$ was increased. The results consistent with $\mathrm{Wu}$ et al. [9] reported that the $\mathrm{T}_{\mathrm{g}}$ of dried $C$. militaris by infrared dryer at $40,50,60$ and $70{ }^{\circ} \mathrm{C}$ at $7 \%$ (d.b) final content of product resulted in the $\mathrm{T}_{\mathrm{g}}$ was range of $38.45-48.40{ }^{\circ} \mathrm{C}$. On the other hand, Santhalakshmy et al. [24] reported that decrease $T_{g}$ while inlet temperature increased in spray drying of jamun fruit juice powder. Normally, at low water activity and high $\mathrm{T}_{\mathrm{g}}$ could control the storage condition and extend shelf life of C. militaris.

\subsection{The color and appearance of $C$. militaris}

The color of dried C. militaris are shown in Table 2 . Increase in drying temperature leading to $L^{*}$ decreased due to the biochemical reaction in food such as enzymatic reaction $[10,25]$. Pretreated sample by boiled water blanching and steaming showed the brown color and darker than other samples due to the browning reaction by thermal stress. Boiled water blanching showed the lowest of $a^{*}$ and $b^{*}$ values due to affected heating and soaking in water simultaneous. This is because after applying heat pretreatment the naturally enzyme population was reduced, plant tissue was softer and more flexible. The appearance of C. militaris at different pretreatment is shown in Fig. 2.
These results correlated well with Hiranvarachat et al. [16]. They reported that blanching in acid had slightly darker red color comparing with fresh carrot and had no significantly difference with blanching in water due to the breaking down of pigments in samples. It was observed that the pretreated sample by desiccating combined with drying at $70{ }^{\circ} \mathrm{C}$ exhibited the lowest $\Delta E$ value, this might be due to some moisture content was evaporated during desiccating pretreatment would result in the shortest drying time, reduce the exposure to thermal stress.

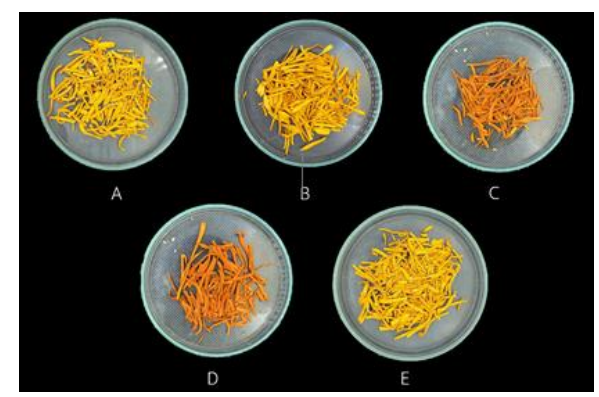

Fig. 2. The appearance of $C$. militaris at different pretreatment: (A) untreated sample, (B) soaking in acid, (C) boiled water blanching, (D) steaming and (E) desiccating.

Fig. 3 shows the micrograph of dried C. militaris. The micrograph could describe the shrinkage of C. militaris during drying. Pretreated samples with desiccating resulted the minimal of shrinkage. This might be the desiccating occur the evaporation of moisture in food matrix. Boiled water blanching samples showed the highest of shrinkage cause the detrimental of cell structure by thermal stress. Hiranvarachat et al. [16] reported that the pretreated carrot by water blanching showed the thinner of cell wall. This resulted could describe some solubilization and degradation of cell components of sample. 
Table 2. The color parameters of dried C. militaris by different conditions.

\begin{tabular}{|c|c|c|c|c|c|}
\hline \multirow{2}{*}{$\begin{array}{c}\text { Temperature } \\
\left({ }^{\circ} \mathrm{C}\right)\end{array}$} & Pretreatment & \multicolumn{4}{|c|}{ Color } \\
\cline { 3 - 6 } & & $L^{*}$ & $a^{*}$ & $b^{*}$ & $\Delta E$ \\
\hline \multirow{5}{*}{50} & Untreated & $46.43 \pm 0.06^{\mathrm{e}}$ & $22.43 \pm 0.21^{\mathrm{d}}$ & $36.27 \pm 0.04^{\mathrm{e}}$ & 34.95 \\
& Soaking in acid & $44.36 \pm 0.24^{\mathrm{g}}$ & $24.35 \pm 0.09^{\mathrm{b}}$ & $35.48 \pm 0.09^{\mathrm{f}}$ & 56.10 \\
& Boiling & $33.49 \pm 0.07^{\mathrm{m}}$ & $21.61 \pm 0.02^{\mathrm{f}}$ & $19.90 \pm 0.11^{\mathrm{k}}$ & 426.85 \\
& Steaming & $34.17 \pm 0.05^{\mathrm{k}}$ & $22.08 \pm 0.04^{\mathrm{e}}$ & $23.56 \pm 0.04^{\mathrm{j}}$ & 338.32 \\
& Desiccating & $47.28 \pm 0.02^{\mathrm{d}}$ & $22.54 \pm 0.05^{\mathrm{d}}$ & $36.38 \pm 0.03^{\mathrm{de}}$ & 29.93 \\
\hline \multirow{5}{*}{60} & Untreated & $47.55 \pm 0.23^{\mathrm{d}}$ & $24.36 \pm 0.07^{\mathrm{b}}$ & $37.10 \pm 0.07^{\mathrm{b}}$ & 26.81 \\
& Soaking in acid & $45.77 \pm 0.04^{\mathrm{f}}$ & $24.33 \pm 0.04^{\mathrm{b}}$ & $34.96 \pm 0.07^{\mathrm{g}}$ & 50.08 \\
& Boiling & $33.88 \pm 0.09^{\mathrm{l}}$ & $24.64 \pm 0.07^{\mathrm{b}}$ & $26.66 \pm 0.05^{\mathrm{i}}$ & 292.54 \\
& Steaming & $35.21 \pm 0.02^{\mathrm{j}}$ & $24.61 \pm 0.03^{\mathrm{b}}$ & $29.07 \pm 0.10^{\mathrm{h}}$ & 234.09 \\
& Desiccating & $48.29 \pm 0.04^{\mathrm{c}}$ & $24.40 \pm 0.41^{\mathrm{b}}$ & $37.89 \pm 0.03^{\mathrm{a}}$ & 19.92 \\
\hline \multirow{5}{*}{70} & Untreated & $49.12 \pm 0.03^{\mathrm{b}}$ & $25.02 \pm 0.11^{\mathrm{a}}$ & $36.82 \pm 0.02^{\mathrm{c}}$ & 24.26 \\
& Soaking in acid & $44.61 \pm 0.05^{\mathrm{g}}$ & $24.33 \pm 0.04^{\mathrm{b}}$ & $36.56 \pm 0.05^{\mathrm{d}}$ & 47.27 \\
& Boiling & $35.55 \pm 0.39^{\mathrm{i}}$ & $24.64 \pm 0.07^{\mathrm{b}}$ & $26.66 \pm 0.05^{\mathrm{i}}$ & 263.72 \\
& Steaming & $37.21 \pm 0.02^{\mathrm{h}}$ & $24.61 \pm 0.03^{\mathrm{b}}$ & $29.07 \pm 0.10^{\mathrm{h}}$ & 202.51 \\
& Desiccating & $49.56 \pm 0.07^{\mathrm{a}}$ & $23.96 \pm 0.05^{\mathrm{c}}$ & $38.01 \pm 0.27^{\mathrm{a}}$ & 14.60 \\
\hline
\end{tabular}

Different letters $(\mathrm{a}-\mathrm{m})$ within the same column indicate a significant different $(\mathrm{P}<0.05)$.

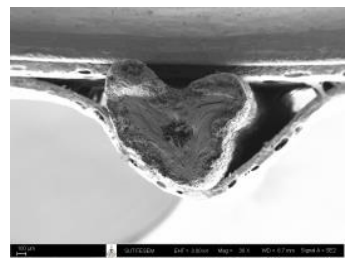

(A)

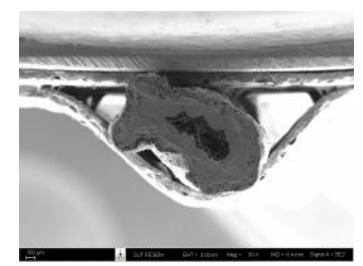

(B)

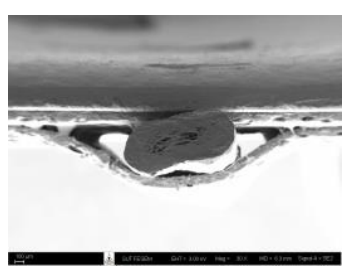

(C)

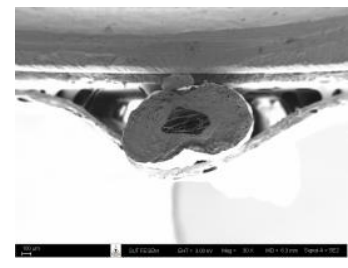

(D)

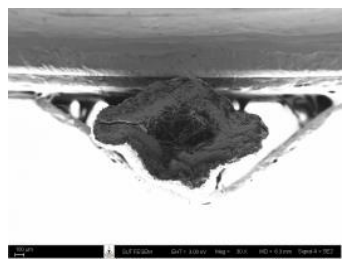

(E)

Fig. 3. The micrograph of dried C. militaris and different pretreatment: (A) untreated sample, (B) soaking in acid, (C) boiled water blanching, (D) steaming and (E) desiccating.

\subsection{Total phenolic compounds}

Fig. 4 shows the total phenolic content (TPC) of dried $C$. militaris by combined effect of pretreatments and drying conditions. The TPC in fresh $C$. militaris was $54.48 \pm$ $2.25 \mathrm{mg} \mathrm{GAE} / \mathrm{g}$ (db.). As drying temperature increase, the TPC increased. This might be because the reduction of drying time could preserve TPC in

C. militaris. The reduction of TPC caused by oxidation reaction and changed in chemical structure of dried sample [26]. Therefore the prolong drying time would deteriorate the phenolic compound. This results consistent with $\mathrm{Wu}$ et al. [10]. They reported that the highest TPC in sample was found in the case of drying temperature at $70{ }^{\circ} \mathrm{C}$ when compared with drying temperature $40-60{ }^{\circ} \mathrm{C}$. Soaking in acid sample showed the highest TPC. In contrast boiled water blanching sample showed the lowest amount of TPC.

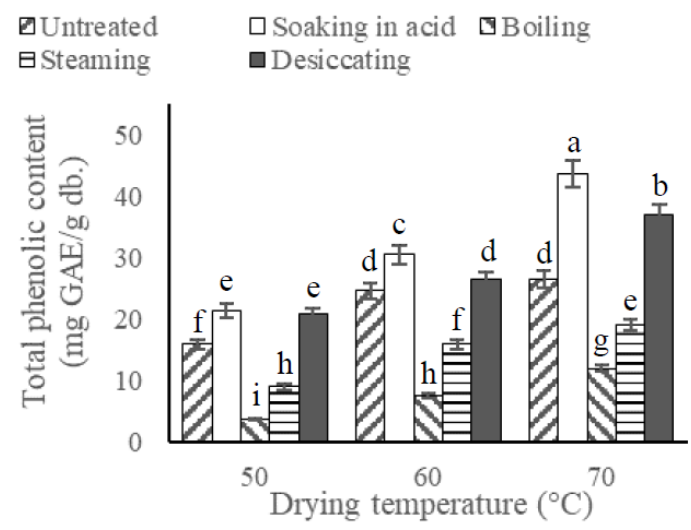

Fig. 4. The total phenolic content of dried C. militaris by different conditions. 


\subsection{Antioxidant activities}

The DPPH scavenging activity and superoxide anion radical scavenging activity of dried $C$. militaris are shown in Fig. 5A and 5B. Increasing drying temperature showed the higher DPPH scavenging activity. Boiled water blanching sample showed the lowest of antioxidant activity. This is because decomposition of bioactive compound by thermal stress. These results correlated well with the total phenolic content of dried $C$. militaris.
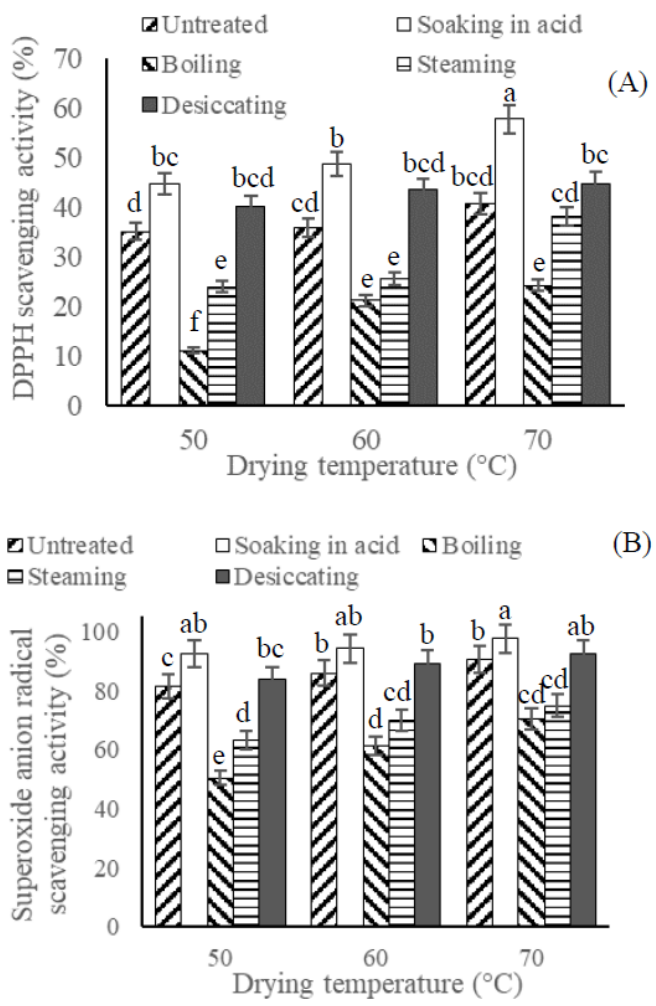

(B)

Fig. 5. The Scavenging activity of DPPH (A) and superoxide anion radicals (B) of dried $C$. militaris pretreated by different method.

In terms of superoxide anion radical scavenging activity of dried $C$. militaris under combination of different pretreatments and drying conditions showed similarity trend with DPPH scavenging activity and total phenolic compound. The vacuum drying temperature at $70{ }^{\circ} \mathrm{C}$ exhibited the superoxide anion radical scavenging activity higher than drying temperature at 50 and $60^{\circ} \mathrm{C}$. The long thermal exposure could degrade the compound that linked the antioxidant activity. Wu et al. [11] reported the superoxide anion radical scavenging activity of dried C. militaris by microwave assisted pulse fluidized bed freeze dryer and freeze dryer had no significant difference about $85.7-90.4 \%$ but in hot air drying showed the value very low. The antioxidant activity had correlation with polysaccharide, phenolics and flavonoids $[25 ; 27]$. The antioxidant mechanism of these compounds was donating a hydrogen atom or single electron to the hydroxyl radical [28]. The hydroxyl radical scavenging was described the inhibition of hydroxyl radical generating and removal hydroxyl radical. The highest superoxide anion radical scavenging activity was found in the case of pretreated by soaking in acid combined with vacuum drying at $70{ }^{\circ} \mathrm{C}$.

\section{Conclusion}

Effects of pretreatment combined with vacuum drying at $50-70{ }^{\circ} \mathrm{C}$ of $C$. militaris were evaluated. Desiccating prior drying process had shortest of drying time and closet of color value with fresh sample. The boiled water blanching prior drying process exhibited the most difference of color, lowest of total phenolic retention and antioxidant activity due to high temperature during pretreatment affecting quality of $C$. militaris. The increasing of drying temperature exhibited the higher glass transition temperature, total phenolic compound and antioxidant activity than low temperature caused from shorter drying time. The recommended condition of dried C. militaris was pretreated by soaking in $0.5 \%$ citric acid and then vacuum drying at $70{ }^{\circ} \mathrm{C}$ under pressure of 60 mbar. It showed the high levels of glass transition temperature, good appearance, the highest total phenolic compound and antioxidant activity.

\section{Acknowledgement}

We would like to thank you the Agricultural Research Development Agency (ARDA), Thailand, ACX Herb Co., Ltd., Thailand and King Mongkut's University of Technology North Bangkok for support my project.

\section{References}

1. S.S. Chiang, Z.C. Liang, Y.C. Wang, C. H. Liang, Effect of light-emitting diodes on the production of cordycepin, mannitol and adenosine in solid-state fermented rice by Cordyceps militaris, Journal of Food Composition and Analysis, 60 (2017): 51-56

2. C. Chen, X.P. Liu, W. Jiang, B. Zeng, W. Meng, L.P. Huang, Anti-effects of cordycepin to hypoxiainduced membrane depolarization on hippocampal CA1 pyramidal neuron, European, Journal of Pharmacological , 796 (2017): 1-6

3. Y. Xiao, G. Xing, X. Rui, W. Li, X. Chen, M. Jiang, M. Dong, Enhancement of the antioxidant capacity of chickpeas by solid state fermentation with Cordyceps militaris SN-18, Journal of Functional Foods, 10 (2014): 210-222

4. F.S.H. Hsiao, Y.H. Cheng, S.K. Wang, Y.H. Yu, Cordyceps militaris hot water extract inhibits lipopolysaccharide-induced inflammatory response in porcine alveolar macrophages by the regulation of mitogen-activated protein kinase signaling pathway, Canadian Journal of Animal Science, 98 (2017): 44-52

5. H. Flordeliza, A.N. Soriano, N.P. Dugos, R.V.C. Rubi, A comprehensive review on the drying kinetics of common tubers, Applied Science and Engineering Progress, 14, 2 (2021): 146-155

6. W. Yan, M. Zhang, L. Huang, J. Tang, A.S. Mujumdar, J. Sun, Studies on different combined microwave drying of carrot pieces, International 
Journal of Food Science and Technology, 45, 10 (2010): 2141-2148

7. K. Thirugnanasambandham, V. Sivakumar, Enhancement of shelf life of Coriandrum sativum leaves using vacuum drying process : Modeling and optimization, Journal of the Saudi Society of Agricultural Sciences, 15 (2016): 195-201

8. T.K. Tran, T. Kirkman, M. Nguyen, Q.V. Vuong, Effects of drying on physical properties, phenolic compounds and antioxidant capacity of Robusta wet coffee pulp (Coffea canephora), Heliyon, 6 (2020): e04498

9. V.T. Nguyen, N.M.Q. Pham, Q.V. Vuong, M.C. Bowyer, I.A. van Altena, C.J. Scarlett, Phytochemical retention and antioxidant capacity of xao tam phan (Paramignya trimera) root as prepared by different drying methods, Drying Technology, 34 (2016): 324-334

10. X.F. Wu, M. Zhanga, Z. Li, Influence of infrared drying on the drying kinetics, bioactive compounds and flavor of Cordyceps militaris, LWT - Food Science and Technology, 111 (2019): 790-798

11. X.F. Wu, M. Zhanga, B. Bhandarid, Z. Lie, Effects of microwave assisted pulse fluidized bed freezedrying (MPFFD) on quality attributes of Cordyceps militaris, Food Bioscience, 28 (2019): 7-14

12. C. Phungamngoen, N. Chiewchan, S. Devahastin, Effects of various pretreatments and drying methods on Salmonella resistance and physical properties of cabbage, Journal of Food Engineering, 115 (2013): 237-244

13. J.I. Maté, M. Zwietering, K. van't Riet, The effect of blanching on the mechanical and rehydration properties of dried potato slices, European Food Research and Technology 209 (1999): 343-347

14. M.S. McCann, J.J. Sheridan, D.A. McDowell, I.S. Blair, Effects of steam pasteurization on Salmonella Typhimurium DT 104 and Escherichia coli $\mathrm{O} 157: \mathrm{H} 7$ surface inoculated onto beef, pork and chicken, Journal of Food Engineering 76 (2006): 32-40

15. D.O. Ukuku, Effect of sanitizing treatments on removal of bacteria from cantaloupe surface, and re-contamination with Salmonella, Food Microbiology, 23 (2006): 289-293

16. B. Hiranvarachat, S. Devahastin, N. Chiewchan, Effects of acid pretreatments on some physicochemical properties of carrot undergoing hot air drying, Food and Bioproducts Processing 89 (2011): 116-127

17. AOAC. Official Method of Analysis 2008.06 (39.1.39) Moisture and Fat in Meats Final Action., (2013).
18. A. Voda, N. Homan, M. Witek, A. Duijster, G.V. Dalen, R.V.D. Sman, J. Nijsse, L.V. Vilet, H.V. As, J.V, Duynhoven, The impact of freeze-drying on microstructure and rehydration properties of carrot, Food Research International, 49 (2012): 687-693

19. X. Cao, M. Zhang, A.S. Mujumdar, Q. Zhong, Z. Wang, Effects of ultrasonic pretreatments on quality, energy consumption and sterilization of barley grass in freeze drying, Ultrasonics Sonochemistry, 40 (2018): 333-340

20. L. Chen, R. Wang, X. Wang, Y. Luo, J. Li, Phenolic contents, cellular antioxidant activity and antiproliferative capacity of different varieties of oats, Food Chemistry 239 (2018): 260-267

21. G. Mao, Y. Zou, W. Feng, W. Wang, T. Zhao, C. Ye, Extraction, preliminary characterization and antioxidant activity of se-enriched Maitake polysaccharide, Carbohydrate Polymers, 101 (2014): 213-219.

22. H.F. Gu, C.M. Li, Y.J. Xu, W.F. Hu, M.H. Chen, Q.H. Wan, Structural features and antioxidant activity of tannin from persimmon pulp, Food Research International, 41, 2 (2008): 208-217

23. E.J. Bassey, J.H. Cheng, D.W. Sun, Novel nonthermal and thermal pretreatments for enhancing drying performance and improving quality of fruits and vegetables, Trends in Food Science \& Technology, 112 (2021): 137-148.

24. S. Santhalakshmy, S.J.D. Bosco, S. Francis, M. Sabeena, Effect of inlet temperature on physicochemical properties of spray-dried jamun fruit juice powder, Powder Technology, 274 (2015): 37-43

25. C.O. Perera, Selected quality attributes of dried foods, Drying Technology, 23, 4 (2005): 717-730

26. L. Valadez-Carmona, C.P. Plazola-Jacinto, M. Hernández-Ortega, M.D. Hernández-Navarro, F. Villarreal, H. Necoechea-Mondragón, G. CeballosReyes, Effects of microwaves, hot air and freezedrying on the phenolic compounds, antioxidant capacity, enzyme activity and microstructure of cacao pod husks (Theobroma cacao L.), Innovative Food Science \& Emerging Technologies, 41 (2017): 378-386

27. S. Wu, F. Li, S. Jia, H. Ren, G. Gong, Y. Wang, Z. $\mathrm{Lv}$, Drying effects on the antioxidant properties of polysaccharides obtained from Agaricus blazei Murrill, Carbohydrate Polymers, 103 (2014): 414417

28. N. Russo, The molecular basis of working mechanism of natural polyphenolic antioxidant, Food Chemistry, 125 (2010): 288-306 